\title{
Strain-Tolerant Cable Using Bi-2212 Superconductor
}

\author{
Peter M. McIntyre, Nikolai Diaczenko, Timothy Elliott, Rainer Soika, Mustafa Yavuz \\ Department of Physics, Texas A\&M University, College Station, TX 77843
}

Leszek Motowidlo

IGC Advanced Superconductor, Waterbury, CT 06704

\author{
Gan Liang \\ Department of Physics, Sam Houston State University, Huntsville, TX 77341
}

\begin{abstract}
The high strain sensitivity of Bi-2212 is a major obstacle for its use as a practical conductor in high-fteld magnet applications. Most efforts to improve the mechanical behavior of Bi-2212 focus on strengthening the sllver matrix by means of alloying. We are reporting on the design and preliminary testing of a strain-tolerant Bi-2212 cable that takes a different approach: Instead of reinforeing the conductor, it channels mechanical stress and strain away from it by prudent design of a Cable-in-Conduit (CIC) assembly. Slx strands of Bl-2212 are cabled around a thin-walled Inconel $X 750$ tube and then sheathed in an outer armor that is drawn onto the 6ont-1 cable configuration.
\end{abstract}

\section{INTRODUCTION}

The strain sensitivity of the BSCCO family of superconductors has been well established. Although the reported values for strain degradation vary somewhat, mostly depending on the particular way of straining the wire or tape, a strain of $3 \%$ is enough to cause significant and irreversible degradation of the critical current $\mathrm{I}_{\mathrm{C}}[1-4]$. Combined with the rather low Young's modulus of silver and therefore also of the composite superconductor, the application of $\mathrm{Bi}$ 2212 in high-field magnet coils faces severe mechanical obstacles. Most efforts on improving the mechanical properties of Bi-2212 wires focus on mechanical reinforcement of the silver matrix by means of alloying (See, for example, Refs.2,4).

The approach described here is different. We cable 6 bare strands of $\mathrm{Bi}-2212$ wire around a hollow Inconel $\mathrm{X}$ 750 tube and then sheath the assembly in an outer armor. A micrograph of a short sample of the cable is shown in Figure 1. In our first cabling run (the results of which are presented in this paper) the outer armor was made of stainless steel (SS 304), but Inconel X 750 will be used in subsequent runs. The six bare strands of wire were twisted around the thin-walled inner tube with a twist pitch of approximately $1.7 \mathrm{~cm}$. The inner thin-walled tube is the crocial part of the design. When the cable is compressed, the inner tube protects the wires by virtue of its soft modulus while the outer armor carries the load. The underlying idea is the concept of stress management, first applied in the development of a 16 Tesla dual dipole magnet at Texas A\&M University [5]. By using a structural material that is

Manuscript received September 27, 1999. This research is supported by the Texas Advaticed Technology Program under Grant \# 160303.

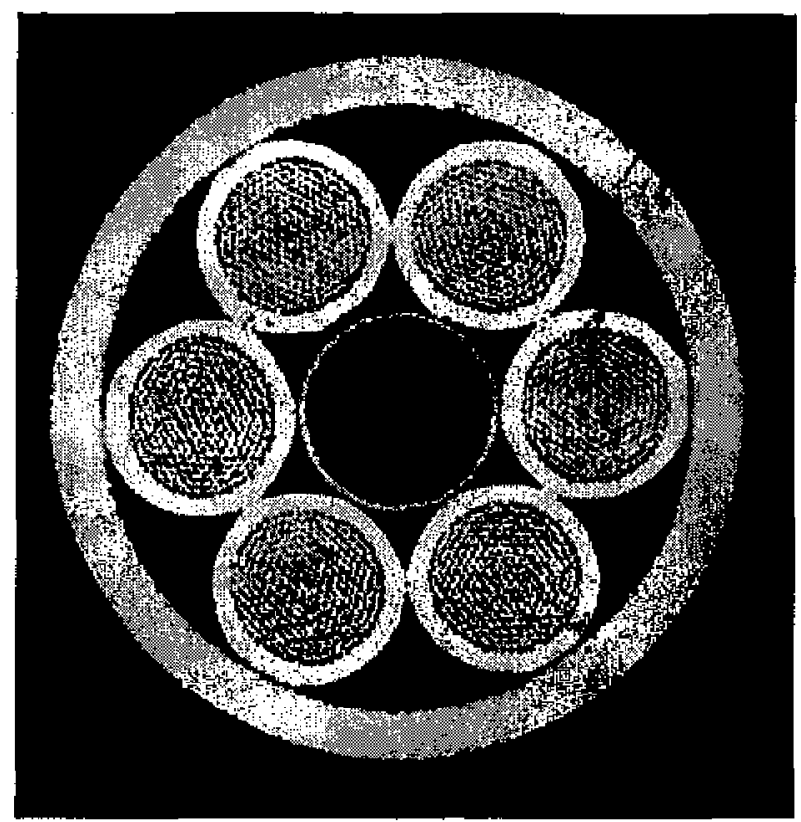

Figure 1. Micrograph cross-section of the cable.

significantly stiffer than the superconduotor external stresses can be bypassed so that they do not strain the fragile cores.

The relationship between magnetic field and stress in a superconducting magnet coil is

$$
\int \frac{B^{2}}{2 \mu_{0}} d V+\int \sigma_{l i} d V=0
$$

where $\sigma_{i l}$ is the stress tensor and the integral is taken over all space. The above theorem stems from plastna physics but also holds true for superconducting magnet coils [6,7]. Thus the mechanical stress in a coil increases with the square of the magnetic field strength. Furthermore, the relationship between stress $s$ and strain $\epsilon$ (in one dimension) is

$$
S=\mathbf{E} \cdot \mathbf{E}
$$

where $E$ is Young's modulus of elasticity. This is just a mathematical expression of the well-known fact that for a given stress materials with a lower elastic modulus strain more than those with a larger modulus. Combined with the 
above theorem, however, one can see how mechanical and structural problems that already require significant attention in many of today's superconducting magnets can caltse even bigger problems for the application of $\mathrm{Bi}-2212$ to high-field magnets. Reported values for Young's modulus of $\mathrm{Bi}-2212$ tapes and wires vary somewhat, but for the linear case range from 52 to $83 \mathrm{GPa}$ for $\mathrm{Ag} / \mathrm{Bi}-2212$, $\mathrm{AgMg} / \mathrm{Bi}-2212$ and $\mathrm{AgNiMg} / \mathrm{Bi}-2212[2,8]$, although it is worth noting that the material is anisotropic [9]. For a typical silver/superconductor ratio of $3: 1$, the mechanical properties of the silver dominate the properties of the composite wire, and the reported values reflect that. At room temperature, silver has a Young's modulus of $79 \mathrm{GPa}$, whereas, for example, steel and Inconel X 750 both have a Young's modulus of $210 \mathrm{GPa}$. By comparison, $\mathrm{Nb}_{3} \mathrm{Sn}$ has a Young's modulus of $162 \mathrm{GPa}[10]$.

It therefore seems prudent to devolop a cable design in which the superconductor is used as just that and does not also have to do double duty as a stuctural material.

We have detailed in a previous paper the results of a finite element analysis as well as the mechanical design and the testing of the Inconel $X 750$ under reaction bake conditions [11]. This paper describes the manufacturing of the structured cable and the testing of short samples.

\section{MANUfacturing}

The Bi-2212 wire used in this project was manufactured by IGC using the oxide-powder-in-tube (OPIT) process [12]. The first batch of wire was a 300 -filament single stack design (Figure 2). This wire was used in the cabling run reported below.

The cross-section of a second batch of wire is shown in Figure 3. It is a double restack design containing 427 filaments, following a design originated by Showa Corp. The dividing structure of alloy-hardened silver provides further reinforcement for the sub-elements. This reinforced wire will be used in future cabling runs.

Manufacturing the cable is a two-step process. First six strands of $\mathrm{Bi}-2212$ are cabled around the hollow inner tube with the 6-on-1 cabling machine shown in Figure 4 . Then

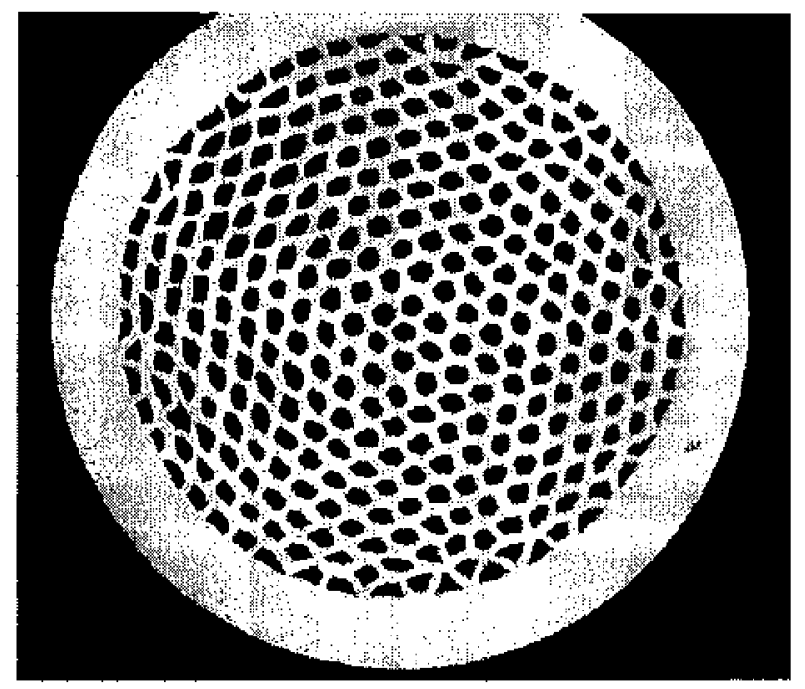

Figure 2, 300 filament IGC Bi-2212 wirc

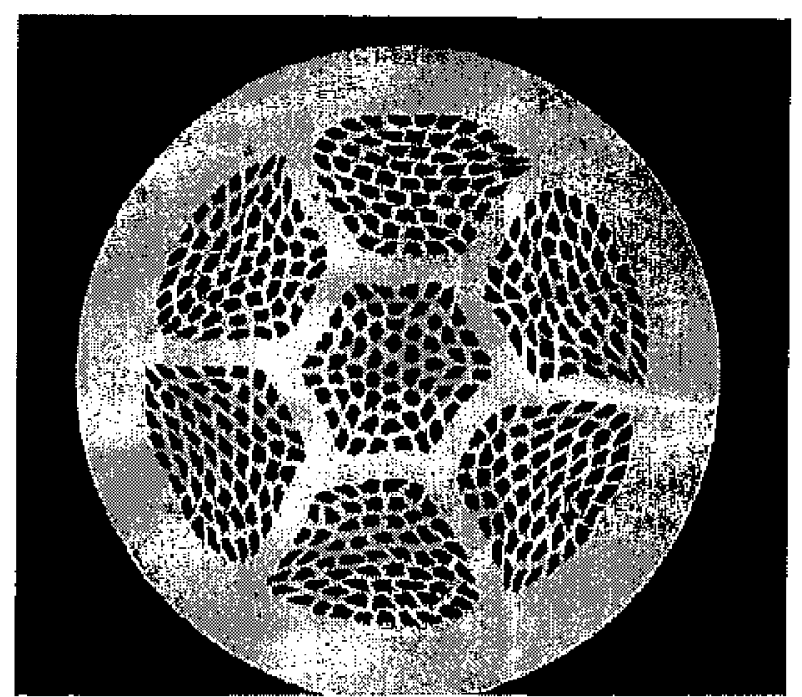

Figure 3. Double restack design

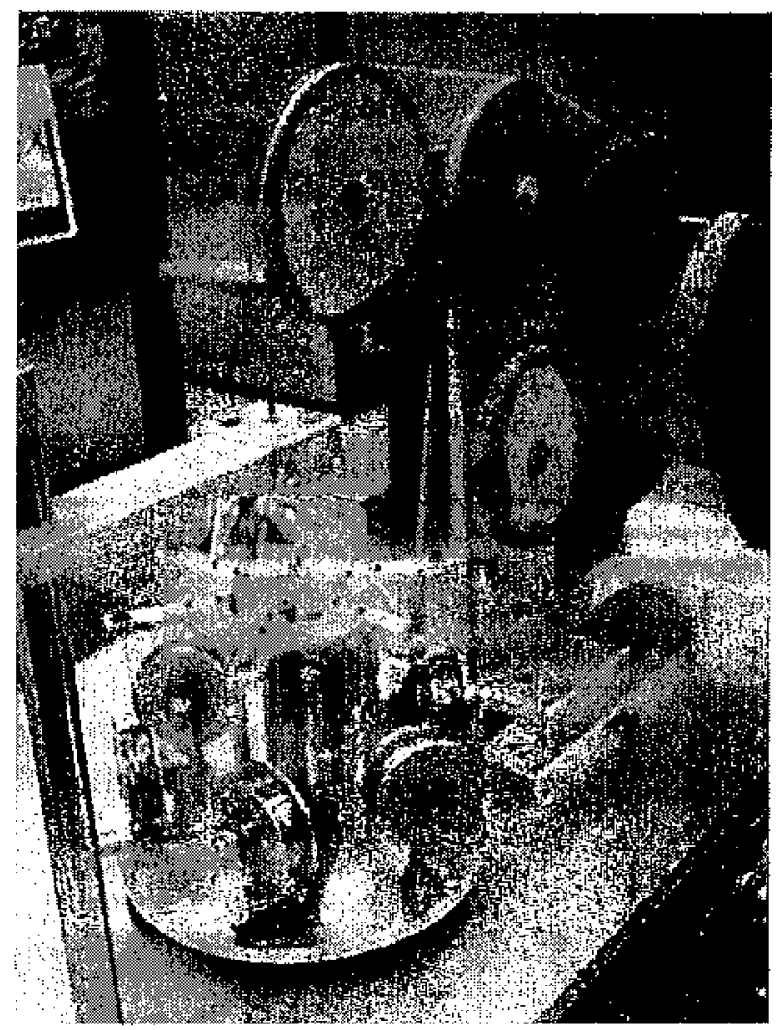

Figure 4. The 6-on-1 cabling machine

the outer armor is drawn onto the 6-on- 1 cable. The relevant dimensions of the cable are given in Table 1.

The 6-on-l cable geometry is a geomctrically stable configuration. Therefore the required winding tension is very small, a tension of about $.5 \mathrm{~kg}$ proved sufficient. This significantly reduces the possibility of damaging the wire. One draw was sufficient to roduce the diameter of the outer tube from $3.40 \mathrm{~mm}$ to $2.95 \mathrm{~mm}$ so that it was snug against the 6-on-1 assembly. 
Table 1. Dimensions of the structured cable.

\begin{tabular}{|c|c|}
\hline \multicolumn{2}{|l|}{$\begin{array}{l}\text { BI-2212 strand } \\
\text { diameter }\end{array}$} \\
\hline $\begin{array}{l}\text { Spring core tube } \\
\text { outside diameter } \\
\text { wall thickness }\end{array}$ & $\begin{array}{l}.83 \mathrm{~mm} \\
.04 \mathrm{~mm}\end{array}$ \\
\hline $\begin{array}{l}\text { Armor tube } \\
\text { before drawing }\end{array}$ & \\
\hline $\begin{array}{l}\text { outside diameter } \\
\text { wall thlckness } \\
\text { after drawing }\end{array}$ & $\begin{array}{r}3.40 \mathrm{~mm} \\
.50 \mathrm{~mm}\end{array}$ \\
\hline $\begin{array}{l}\text { outside dlameter } \\
\text { inside dlameter } \\
\text { wall thickness }\end{array}$ & $\begin{array}{l}2.95 \mathrm{~mm} \\
2.45 \mathrm{~mm} \\
.50 \mathrm{~mm}\end{array}$ \\
\hline
\end{tabular}

It is worth noting that the armor tube is not constricted in its inward motion during the drawing process up to the very last moment at which it starts touching the 6 wires. Thus it is easily possible to achieve an area reduction in the armor tube during drawing (33\%) that is greater than the standard ( $7 \%$ ) for area reduction during wire drawing.

Once the outer armor is drawn onto the cable, it is ready to be heat treated.

The issue of oxygen release during partial melt and the dependence of the melting point on oxygen partial pressure is fairly complex [12-15]. Since some oxygen is released as the partial melt takes place and reabsorbed upon cooling down, a geometry that constricts the flow of oxygen can temporarily increase $\mathrm{pO}_{2}$ and thus shift the melting point. The more volume the oxygen has to expand into as it is released from the wire, the less the increase in partial pressure will be. It is therefore important to make the cable design as permeable to oxygen flow as possible. We perforated the inner tube using a laser trimmer (Electro Scientific Industries, Model 44) to achieve this. The perforated holes are about $2.5 \mathrm{~cm}$ apart and have a diameter of about .05 mm. One laser shot perforates both sides of the tube.

\section{TEST RESIRTS}

The heat treatment and short sample tests were carried out by IGC. Three samples as shown in Figure 5 were heat treated and then tested. The samples were produced from a Im length of un-reacted cable that was cut into short $(\sim 5$ $\mathrm{cm}$ ) pieces. About $1 \mathrm{~cm}$ was then trimmed off each end by parting the armor tube.

The critical current of one of the wires in the cable was then measured and compared to results for bare wire from the same batch (Figure 6). The benchmark measurements were made on two sets of wires, one being taken from ahead of the wire used in the cable, one from behind the wire used in the cable. The criterion was the standard $\mathrm{E}<1$ $\mu \mathrm{V} / \mathrm{cm}$. The measurements were made in self-field at $4.2 \mathrm{~K}$ using the four-point method. As can be seen, the critical currents of the wires in the cable samples are in between the two control groups. Since there is generally a variation of $I_{C}$ along the length of a batch, it is difficult to draw any definite conclusions. However the fact that the $\mathrm{I}_{\mathrm{C}}$ 's of the cable short samples are in between the results for the bare

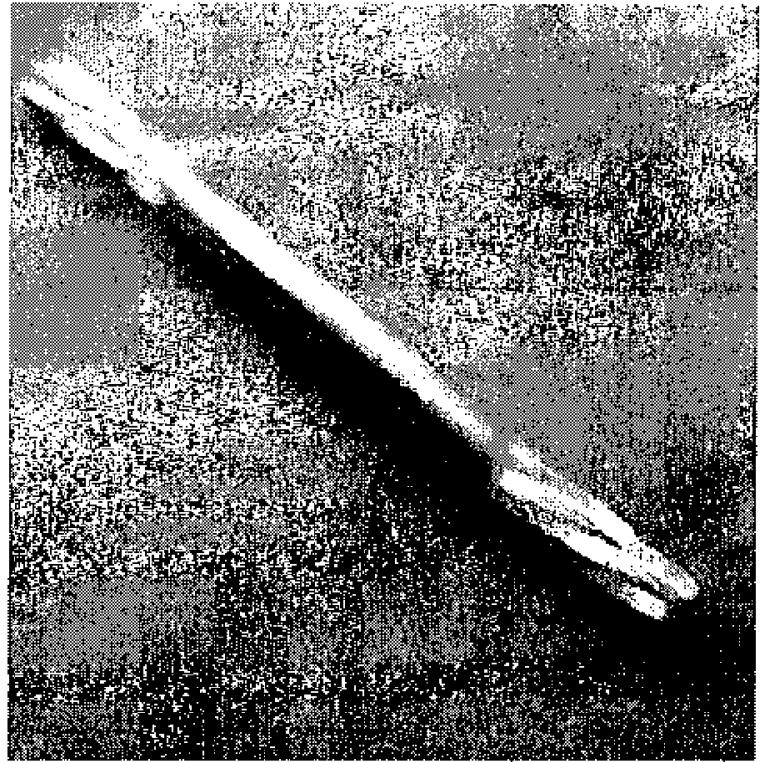

Figure 5. Shott sample with exposed ends

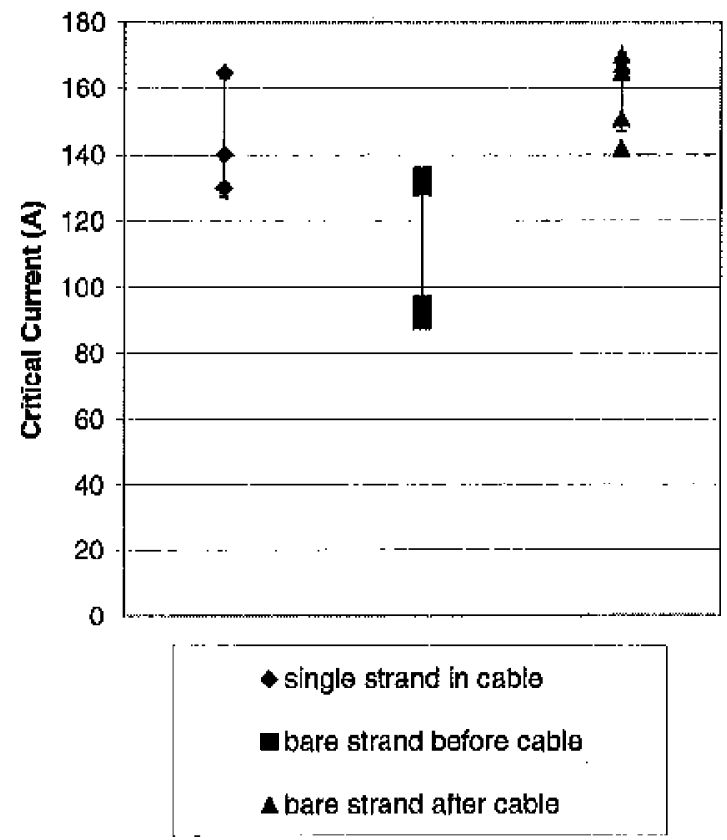

Figure 6. Measurct short-sample current in single wires within a structured cable, compared to that in un-cabled wires.

wire taken from different locations indicates that there is no fundamental flaw in the design.

An important issue for a practical cable is its bending behavior. We have successfully bent a dummy cable of our design that uses copper wires instead of superconductor. Figure 7 shoes two samples that were bent around a diameter of $\sim 2.5 \mathrm{~cm}$. We did not observe any significant degradation which we attribute to the fact that the 6 cables are free to slide within the cable. 


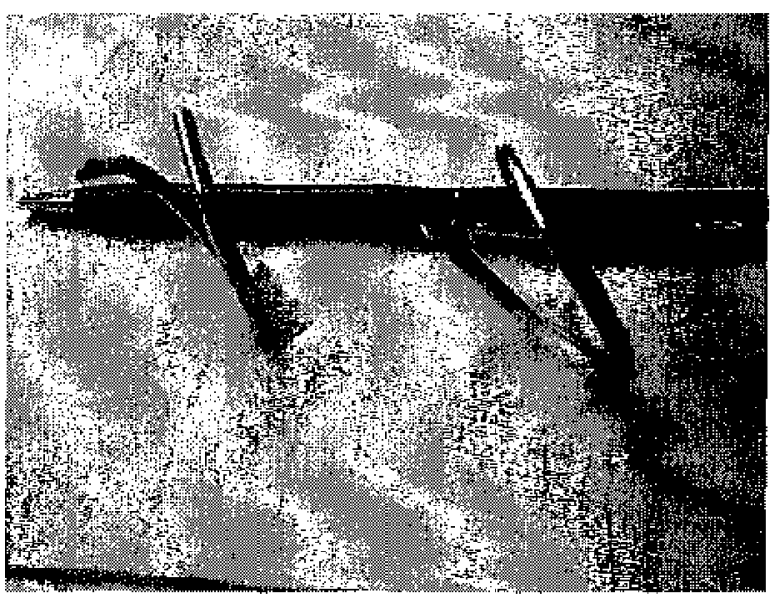

Figure 7. Bending test samples

\section{CONCLUSIONS AND OUTLOOK}

Short samples of the strain-tolerant Bi-2212 cable have been fabricated with no apparent degradation in $\mathrm{I}_{\mathrm{C}}$. The hardware required for the production of the cable is set up and operational and the in-house furnace for the heat treatment of the samples is now in place. The next steps in the development are the fabrication and testing of longer lengths of the cable and the winding of a small test coil. The longer samples and the test coil will then undergo mechanical load tests to determine the behavior of the cable under stress.

\section{ACKNOWLEDGEMENTS}

We would like to thank Prof. Michael Weimer of the Department of Physics at Texas A\&M University for the use of his laser trimmer. The authors are thankfill to Jeremy Steinshnider for his assistance with the device.

We would also like to thank Prof. Ted Hartwig of the Department of Mechanical Engineering at Texas A\&M University for the use of his draw bonch and swaging machine.

Furthermore, we thank the glass shop in the Chemistry Department at Texas $\Lambda \& M$ University for their help in outting the cable into short samples.

\section{REFERENCES}

[1] J. Tenbrink and H. Krauth, Manufacture and Properties of Bi2212. Based Ag-Shathed Wires, in: Bisınth-Based Iligh-Temperature Superconductors (chapter 16), edited by H. Maeda and K. Togano, Marcel Dekker, New York (1996)

[2] R. Wesche, A.M. Fuchs, B. Jakob and G. Pasztor, Axial and bending strain effects in $\mathrm{Ag}$ and $\mathrm{AgNiMg} / \mathrm{Bi}-2212$ wires, Cryogenics, Volume 36, Number 6, pp. 415-426 (1996)

[3] P.E. Richens, H. Jones, M. Van Cleemput, and D.P. Hampshire, Strain Dependenes of critical currents in commercial superconductors, IEEE Trans. Appl, Supercond., Volunie 7, Nunber 2, pp. 1315$1318(1997)$

[4] K. Katagiti ct al, Tensile strain/tratsiverse compressive stress dependence of critical current in $\mathrm{Bi}(2212)$ supercondluctìng tapes with Zr-reinforced Ag sleath, Cryogenics, Volume 38, Number 3, pp. $283-288(1998)$
[5] T, Elliod et al, 16 Tesla $\mathrm{Nb}_{3} \mathrm{Sn}$ Dipole Development at Texas A\&M University, IEEE Trans. Appl. Supercond, Volume 7, Number 2, pp. 555-557(1997)

[6] Longmire, C.I n, Flenentary plasma physics, Section 3.7, WilcyInterscienec, Now York (1963)

[?] Wilson, M. N., Supereonducting Magnets, Chapter 9, Clarendon Pross, Oxford (1983)

[8] J. Selwwartz ot al, Mechanical Properties and Strain Effects in $\mathrm{Bi}_{2} \mathrm{Sr}_{2} \mathrm{CaCh}_{2} \mathrm{O}_{\mathrm{x}} / \mathrm{AgMg}$ Composite Conductors, IEEE Trans. A.ppl, Supercond, Volume 7, Number 2, pp. 2038-2041 (1997)

[9] K,C. Gotelia ot al, Strength and Flexibility of Bulk High-T Superconductors, [EEE Trans. Appl, Supercolld, Volume 7, Number 2, pp. 1307-1310 (1997)

[10] Iwasa, Y., Case Studies in Superconducting Magnets, p. 389, Plenum Press, New York (1994)

[11] N. Diaczenko et al, Stress Management of HTS Conductor, IEEE Trans, Appl. Supereond., Volume 9, Number 2, pp. 142-145 (1999)

[12] L, R. Motowidlo, G. Galinski, G. Ozeryansky, W. Zhang, attd E.E. Hellstrom, Dependience of critical Current Density on Filament Diameter it Round Multifilament Ag-Sheathed BSCCO Wires Processed in $\mathrm{O}_{2}$, Agpl. Phys. Lett., 65(21), (1994)

[13] T. Kanai and T. Knmo, Control of oxygen relense from Bi-2212 ghase in a partial melt zirocess, Supereond. Sei. Technol. 6, pp.510513,1993

[!4] T, Kanai, N. Inoue, and T Kamo, Effect of oxygen partial pressure and melting temperature on Ag ssheathed Bi-2212 wires, J. Mater. Res., Vol, 9, No. 6, pp. 1363-1368 (1994)

[15] P.V.P.S.S. Sastry, A.D. Robertson, and A.R. West, Instability of Bi-Sr-Ca-Cu-O supercondnctors under high oxygen pressure, Physica C 250 (1995), pp. 82-86

[16] H. Kumakura, H. Kitaguchi, K. Togano and N. Sugiyama, Effect of high oxygen partial pressure heat trcatunerit on the superconducting properties of $\mathrm{Bi}_{2} \mathrm{Sr}_{2} \mathrm{CaCl}_{2} \mathrm{O} / \mathrm{Ag}$ tapes, $\mathrm{J}$. Appl. Physies 80 (9), pp. 5162-5168 (1996) 